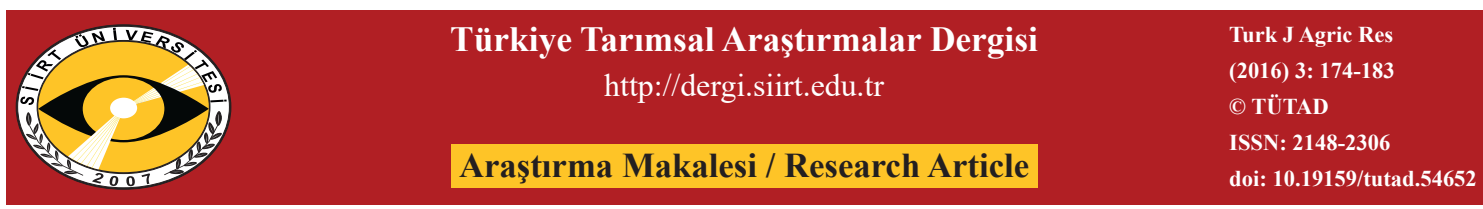

\title{
Bartın İli Meralarının Bazı Özellikleri
}

\author{
Ferat UZUN ${ }^{1 *}$, Fatih ALAY ${ }^{2}$, Kadir İSPIRL $\dot{I}^{2}$ \\ ${ }^{\text {I} O n d o k u z ~ M a y l s ~ U ̈ n i v e r s i t e s i, ~ Z i r a a t ~ F a k u ̈ l t e s i, ~ T a r l a ~ B i t k i l e r i ~ B o ̈ l u ̈ m u ̈, ~ S a m s u n, ~ T U ̈ R K I Y E ~}$ \\ ${ }^{2}$ Karadeniz Tarımsal Araştırma Enstitüsü, Samsun, TÜRKIYYE
}

\begin{abstract}
Geliş Tarihi/Received: 19.07 .2016
Kabul Tarihi/Accepted: 23.08 .2016

*Sorumlu yazar/Corresponding author: fuzun@omu.edu.tr

Özet: Bartın ili, Merkez ilçesine bağlı 15 köyün meralarının bazı vejetasyon özelliklerini belirlemek amacı ile 2016 yılında yapılan bu çalışmada modifiye edilmiş tekerlekli lup (halka) metodu kullanılmıştır. Vejetasyon etüdü yapılan meralarda toplam olarak 128 tür tespit edilmiştir. Tespit edilen türlerin 18 adedi azalıcı, 10 adedi çoğalıcı, 100 adedinin ise istilacı tür (89 adedinin otsu ve 11 adedinin ise çalı-ağaç) olduğu belirlenmiştir. Araştırmanın yürütüldüğü meraların bitkiyle kaplı alan oranı ortalamas1 \% 93.57'dir. Mera vejetasyonlarında yer alan türlerin kalite dereceleri bakımından sınıflandırılmas neticesinde botanik kompozisyondaki; azalıcılar, çoğalıcılar ve istilacı türlerin oranları ise sırasıyla $\% 15.52, \% 15.59$ ve \% 68.89 olarak belirlenmiştir. Araştırmadan elde edilen sonuçlara göre çalışılan meraların 1 adedi "Çok iyi”, 1 adedi "İyi”, 6 adedi "Orta" ve 7 adedi ise "Zayıf" mera durumu sınıfına girmiştir. Mera sağlığı açısından yapılan sınıflamada ise 14 mera "Sağlıklı", 1 mera ise "Sorunlu" olarak belirlenmiştir. Çalışılan meralarda, bitkilerin toprağı kaplama oranı ile toprak derinliği $\left(r=0.553^{*}\right)$ ve otlanma derecesi ile mera toprağının sıkışması $\left(r=0.587^{*}\right)$ arasında pozitif ilişkiler bulunmuştur. Bu sonuçlara göre; çalışılan meraların yaklaşık yarısı dikkatli bir şekilde kullanılmaya, diğer yarısı ise acilen ıslah programına dâhil edilmeye ihtiyaç duymaktadır.
\end{abstract}

Anahtar Kelimeler: Mera durumu, mera sağlığı, otlanma derecesi, toprak sıkışması, istilacı türler

\section{Some Properties of Rangelands in Bartın Province}

Abstract: This study was conducted to determine some vegetation characters of 15 village rangelands in Bartın province in 2016. In the study, modified wheel point method with loop was used. Totally 128 plant species were determined in studied rangelands. This plant species were also divided into 3 different successional groups: i) 18 species were decreases, ii) 10 species were increasers, 100 species were invaders ( 89 species were herbaceous and 11 species were shrubs-trees). In the experiment rangelands, plant coverage rate was $93.57 \%$. Considering the different successional groups, which had influential effect to pasture quality, decreasers, increasers, and invaders had $15.52 \%, 15.59 \%$ and $68.89 \%$, respectively. The results from the present study indicated that 1, 1,6 and 7 rangelands are "Very good", Good", "Fair" and "Poor" conditions based on the rangeland condition classes, respectively. On the other hand, 14 and 1 rangelands were found as "Healthy" and "Unhealthy" in health categories. There were significant correlations between plant cover and soil depth $\left(r=0.553^{*}\right)$ and grazing level and soil compaction $\left(r=0.587^{*}\right)$ in studied rangelands. According to these results half of the rangelands must be used carefully, while other half are need improving immediately.

Keywords: Rangeland condition, rangeland health, grazing level, soil compaction, invader species

\section{Giriş}

Birçok faktörün etkisi altında bulunan mera ekolojisi süreklilik arz eden bir dinamizm içerisindedir. Meraların bu dinamizmi üzerine canlı ve cansız birçok faktör etkili olmakla birlikte, en etkili faktör şüphesiz ki başta yağış olmak üzere o yörede hüküm süren iklim şartlarıdır. Meralarda otlayan hayvan sayısı ile hayvanların tür kompozisyonu da mera vejetasyonlarına çok önemli derecede etkide bulunan unsurlardır. İklim 
şartlarına etki etmek insanoğlu için hâlihazırda mümkün olmadığından; doğru amenajman planlamaları, meraların dinamizmlerini ve üretkenliklerinin devamı ve hatta artırılması noktasında etki edebileceğimiz tek unsurdur. Amenajman ve 1slah çalışmaları uygulanarak yönlendirilen mera dinamizminin yönü zaman zaman kontrol edilmeli, istikametten sapmalar görüldüğünde, zamanında ve doğru müdahalelerle istenilen yöne sevki sağlanmalıdır.

Meralarda yapılacak her türlü amenajman ve ıslah çalışmalarının doğru bir şekilde planlanması, yürütülmesi ve istenilen sonuçların elde edilebilmesi için meraların bitki ve toprak yapısı hakkında yeterli bilgiye sahip olunması, başarı için en önemli adımdır. Meraların bitkisel varlığı, o meralarda uygulanacak olan otlatma planının şekillenmesinde en belirleyici unsurdur. Mera topluluğunda yer alan bitkilerin karakteristikleri, o meranın ortaya koyacağı üretim miktarı, bu üretimin y1l içerisindeki değişim seyri ve üretim kalitesi, hatta bu meradan en iyi faydalanabilecek hayvanların türü ve sayısının tespiti noktasında en temel göstergedir (Beskow, 2001). Mera durumu ortaya konulan meraların, değişik yağış kuşakları için hazırlanan çizelgelerden faydalanılarak otlatma gücünün kolay ve hızlı bir şekilde hesaplanabilmesi ve amenajman planlamalarının doğru bir şekilde yapılabilmesi mümkündür (Bakır, 1999; Koç ve ark., 2003; Holechek ve ark., 2010). Bu noktadan hareketle meraların bitkisel yapısında meydana gelen herhangi bir değişim, bu alanlarda gerçekleşen bitkisel üretimin miktarını, buna bağlı olarak da mera amenajman planlarını doğrudan etkilemekte, zaman zaman revize edilmelerini gerektirebilmektedir.

Ülkemizde mera vejetasyonlarının durum sinıflaması 4342 sayılı "Mera Kanunu ve Yönetmeliği’ne göre meraların kalitelerinin belirlenmesinde, meraların vejetasyonlarını oluşturan bitki türlerinin tespiti ve bunların sınıflandırılmasını esas almaktadır (Anonim, 1998). Bu kriterler çerçevesinde sınıflandırılan bitki türlerinin oransal miktarına bağlı olarak ta meraların kalite dereceleri ortaya konulmaktadır. $\mathrm{Bu}$ sinıflamaya ek olarak vejetasyonda yer alan bitkilerin toprağı kaplama oranları da dikkate alınarak, meraların su ve rüzgar erozyonuna olan hassasiyetleri de ayrica belirlenmektedir (David ve ark., 2002; Koç ve ark., 2003). Temel olarak meraların envanterinin çıkarıldığı bu çalışmalardan elde edilen veriler, bizzat Gida Tarım ve Hayvancılık Bakanlı̆̆ı'nın bizzat kendisinin veya yine aynı bakanlığın, Mera Kanunu'nun 12 . maddesine göre "1slah edilmek suretiyle mera olarak kullanilabilecek alanlar, gerekli 1slah işlemlerini taahhüt eden özel ve tüzel kişilere kiralanabilir" hükmü gereğince yapacağ uygulamalar neticesinde bu meraları kiralayanların yapacakları ıslah çalışmalarına 1şık tutmaktadır.

$\mathrm{Bu}$ kapsamda ülkemizin birçok ilinde yapılan çalışmaların devamı olarak Bartın ilinin Merkez ilçesine bağlı bazı doğal meraların; amenajman ve 1slah çalışmalarına temel teşkil edecek bitki örtüsü, toprak ve diğer bazı özellikleri belirlenmiştir. Çalışmada ayrıca, bu meralarda otlayan hayvanlar ile vejetasyon arasındaki temel ilişkiler de ortaya konulmuştur. Diğer yandan yapılan bu çalışma ile daha önceki yıllarda bizzat Bakanlığın kendisi tarafindan ıslah çalışması yürütülen Kabagöz ve Yeğenli köyleri meralarının son durumu ortaya konulacaktır.

\section{Materyal ve Yöntem}

$\mathrm{Bu}$ çalışma; Bartın ili Merkez ilçe sınırları içerinde, $41^{\circ} 47^{\prime}-41^{\circ} 65^{\prime} \mathrm{N}$ ve $32^{\circ} 16^{\prime}-32^{\circ} 44^{\prime} \mathrm{E}$ koordinatları arasında yer alan ve rakımları 8 ile $166 \mathrm{~m}$ arasında değişen 13 köyün (Çakırkadı, Beşköprü, Çiftlik, Akmanlar, Kocareis, Tabanözü, Gökçekıran, Çukurbük, Çaybükü, Ahmetler, Dallıca, Çeştepe, Dirazlar) doğal, 2 köyün (Kabagöz ve Yeğenli) ise ıslah edilmiş meralarında (Şekil 1), 2016 yılı Mayıs ayının ikinci yarısında yürütülmüştür.

Araştırma alanına ait uzun yıllar (1950-2015) iklim verileri Şekil 2'de sunulmuştur. Thornthwaite (1948)'a göre nemli-mezotermal iklim sınıfına giren Bartın ilinin; uzun yıllara ait ortalama yıllık yağış toplamı $1040.5 \mathrm{~mm}$, ortalama sicaklık değeri ise $12.8{ }^{\circ} \mathrm{C}$ 'dir. İklim diyagramından da anlaşılacağı üzere, yağış rejimi diğer birçok ilimize göre daha düzenlidir. En kurak aylarda bile yağış miktarı oldukça fazladır. Ancak, sicaklık değerlerinin daha yüksek gerçekleştiği yaz dönemine ait aylarda gerçekleşen yağış miktarları yılın en düşük değerleridir. Bu nedenle bölgedeki meraların ana kaba yem kaynağı olan serin iklim yem bitkilerinin bu dönemde dormant hale geçmeleri nedeniyle meraların kaba yem üretiminde düşüşler meydana gelmektedir.

Meraların vejetasyon ölçümleri, modifiye edilmiş tekerlekli lup (halka) metodu kullanılarak meralardaki hâkim bitkilerin çiçeklenme evresinde Koç ve Çakal (2004)'ın ifade ettiği şekilde belirlenmiştir. Bitki teşhisinde Davis (1970)'ten faydalanılmıștır. Okuma neticesinde tespit edilen bitki türleri azalıcılar, çoğalıcılar ve istilacılar olmak üzere 3 sınıfa ayrılmışlardır. Tespit edilen bitkilerden azalıcıların tamamı ve çoğalıcıların ise \% 20'si dikkate alınarak çalıșılan meralarda mera durumu sınıflaması yapılmıştır. Bitki örtüsünün toprağı kaplama oranı, vejetasyon etüdü sırasında bitkiye rastlanan nokta sayısının ölçülen toplam 


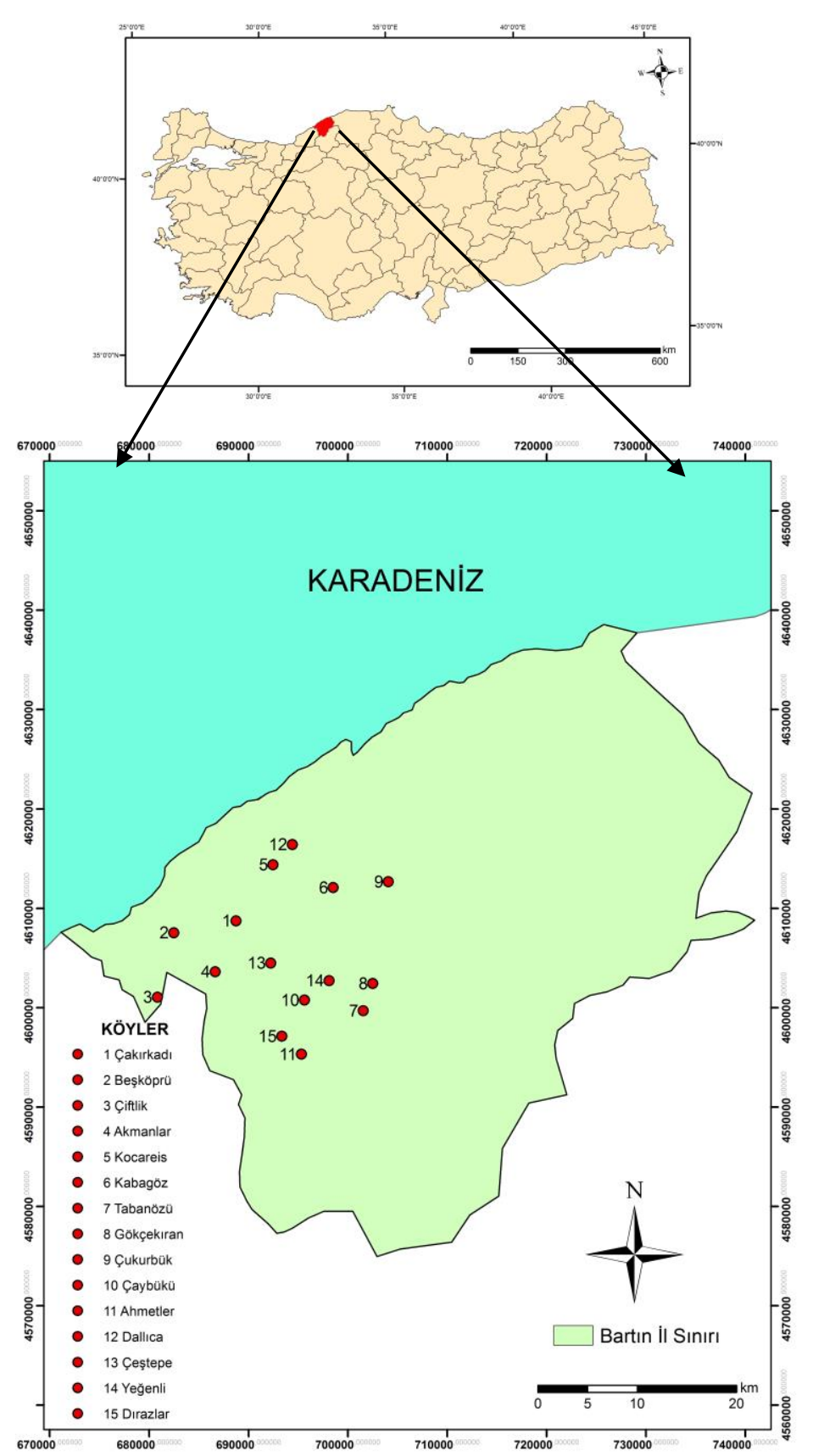

Şekil 1. Bartın ili Merkez ilçesinin lokasyon haritası

nokta sayısına oranlanması ile belirlenmiştir (Gökkuş ve ark., 2000). Okunan her bir bitki türüne ait değerler, toplam bitki sayısına oranlanarak türlerin botanik kompozisyondaki oranları tespit edilmiştir. Meraların durum ve sağlık sınıflamaları, Koç ve ark. (2003) ile Holechek ve ark. (2010) tarafindan ifade edilen kriterlere göre yapılmıştır (Tablo 1). Meraların sağlık sınıflaması için, çalışmadan elde edilen değerler, Koç ve Çakal (2004)'in geliştirdiği regresyon eşitliğinden $\quad(y=0.978 x-24.042$, $\left.R^{2}=0.905\right) \quad$ yararlanilarak transekt metoduna transfer edilmiştir. Transfer edilen bu değerlere göre Koç ve ark. (2003)'nın önerdiği şekilde meraların sağlık sınıflaması yapılmıştır. Bir büyükbaş hayvan birimi (BBHB)'nin ihtiyaç duyduğu mera alanı Bakır (1999) ve Holechek ve ark. (2010)'na göre hesaplanmıştır.

Meraların eğimi, düz (\% $0-1)$, hafif eğimli (\% 2-5), orta eğimli (\% 6-11), dik eğimli (\% 1219), çok dik eğimli (\% 20-29) ve arızalı (>\% 30); toprak derinliği, çok sı ̆ $(\leq 19 \mathrm{~cm})$, sı ̆ $(20-49 \mathrm{~cm})$, orta derin $(50-89 \mathrm{~cm})$, derin $(90-149 \mathrm{~cm})$ ve çok 
derin $(150 \leq \mathrm{cm})$; otlatma derecesi ile mera toprağında meydana gelen sıkışma ise mera vejetasyonlarında yer alan bitkiler ve mera toprağ1 üzerinde yapılan gözlemlere dayanarak her iki özellik için de sırasıyla, yok (0), çok hafif (1), hafif (2), orta (3), yoğun (4) ve çok yoğun (5) olarak sınıflandırılmıştır (Anonim, 2005).

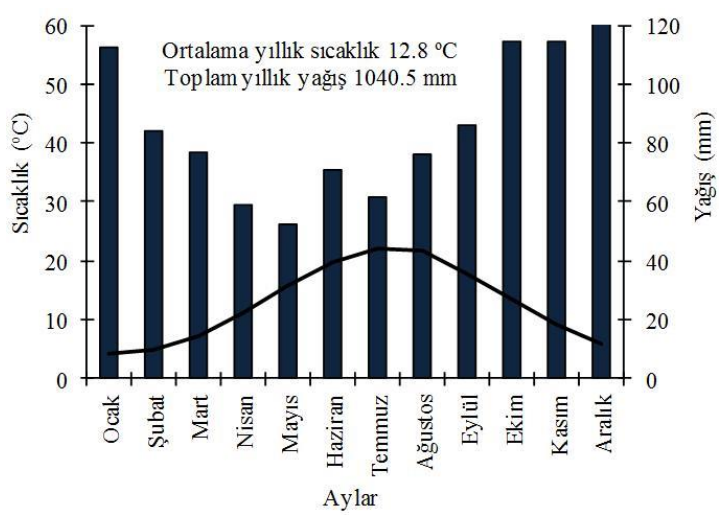

Şekil 2. Bartın ilinin uzun yıllara ait sıcaklık (-) ve yağış (】) diyagramı (Anonim, 2016a)

Tablo 1. Mera durumu ve sağlığı değerlendirmesi

\begin{tabular}{lccc}
\hline \multicolumn{2}{c}{ Durum sınıflaması } & Mera sağlığı sınıflaması \\
\hline $\begin{array}{l}\text { Hesaba katılan } \\
\text { türlerin oranı } \\
(\%)\end{array}$ & $\begin{array}{c}\text { Durum } \\
\text { sinıfı }\end{array}$ & $\begin{array}{c}\text { Toprağ1 } \\
\text { kaplama } \\
\text { oran1 (\%) }\end{array}$ & $\begin{array}{c}\text { Sağlık } \\
\text { sinıfı }\end{array}$ \\
\hline $76-100$ & Çok iyi & $>40$ & Sağlıklı \\
$51-75$ & İyi & $30-40$ & Riskli \\
$26-50$ & Orta & $<30$ & Sorunlu \\
$0-25$ & Zayıf & & \\
\hline
\end{tabular}

\section{Bulgular ve Tartışma}

Vejetasyon etütlerinde 128 farklı tür tespit edilmiştir. Çalı ve ağaçlar (\% 41.11) hariç tutulursa, tespit edilen türlerin 31 adedinin (\% 20.98) baklagil, 18 adedinin (\% 15.82) buğdaygil ve 69 adedinin (\% 22.09) diğer familyalara ait türler olduğu belirlenmiştir. Genel olarak meraların botanik kompozisyonundaki en yüksek oranı, Çomakli ve ark. (2012)'nın da ifade ettiği gibi, daha fazla sayıda familyalara ait türler ihtiva eden ve diğergiller olarak ifade edilen grup oluşturmaktadır

Çalışılan mera vejetasyonlarda en fazla yer alan baklagiller, Trifolium repens ( $\%$ 6.43), Trifolium resupinatum $(\% \quad 1.76), \quad$ Lotus corniculatus $(\%$ 1.56) ve Medicago minima (\% 1.49) olurken; Cynodon dactylon (\% 7.04), Lolium perenne (\% 2.79), Festuca ovina (\% 1.50) ve Dactylis glomerata (\% 0.99) ise en fazla rastlanılan buğdaygiller olmuştur. Diğer familyalardan ise Bellis perennis (\% 2.40), Blysmus compressus (\% 2.08), Carex acuta (\% 1.97) ve Trifolium resupinatum (\% 1.76) en fazla rastlanılan türler olmuştur (Tablo 2 ve Tablo 3).

Belirlenen türlerin kalite derecelerine göre dağılımına göre bitkilerin 18 adedinin (\% 15.52) azalıcı, 10 adedinin ( $\%$ 15.59) çoğalıcı, 89 adedinin otsu (\% 27.78) ve 11 adedinin çalı-ağaçs1 (\% 41.11) istilacı türlerden oluştuğu görülmektedir. Çalışılan meraların ortalaması

Tablo 2. Azalıcı ve çoğalıcı türlerin toprağı kaplama (TKO) ve botanik kompozisyondaki oranları (BKO) (\%)

\begin{tabular}{|c|c|c|c|c|c|}
\hline Tür & TKO & $\mathrm{BKO}$ & Tür & TKO & $\mathrm{BKO}$ \\
\hline \multicolumn{6}{|c|}{ Azalicilar } \\
\hline Trifolium repens & 6.02 & 6.43 & Koeleria cristata & 0.21 & 0.23 \\
\hline Lolium perenne & 2.61 & 2.79 & Vicia cracca & 0.21 & 0.23 \\
\hline Lotus corniculatus & 1.46 & 1.56 & Hordeum bulbosum & 0.18 & 0.19 \\
\hline Poa pratensis & 1.14 & 1.22 & Poa trivialis & 0.11 & 0.11 \\
\hline Dactylis glomerata & 0.93 & 0.99 & Trifolium hybridum & 0.07 & 0.08 \\
\hline Sanguisorba minor & 0.45 & 0.48 & Bromus tomentellus & 0.05 & 0.06 \\
\hline Trifolium pratense & 0.43 & 0.46 & Trifolium physodes & 0.05 & 0.06 \\
\hline Lotus tenius & 0.32 & 0.34 & Agropyron cristatum & 0.02 & 0.02 \\
\hline Medicago sativa & 0.23 & 0.25 & Trifolium trichocephalum & 0.02 & 0.02 \\
\hline Toplam & & & & 14.52 & 15.52 \\
\hline \multicolumn{6}{|c|}{ Çoğalıcılar } \\
\hline Cynodon dactylon & 6.59 & 7.04 & Coronilla scorpioides & 0.63 & 0.67 \\
\hline Plantago lanceolata & 3.27 & 3.28 & Poa bulbosa & 0.57 & 0.61 \\
\hline Festuca ovina & 1.41 & 1.50 & Plantago major & 0.23 & 0.25 \\
\hline Dorycnium graecum & 0.93 & 0.99 & Stipa bromoides & 0.23 & 0.25 \\
\hline Medicago lupulina & 0.82 & 0.88 & Lathyrus czeczottianus & 0.11 & 0.11 \\
\hline Toplam & & & & 14.59 & 15.59 \\
\hline Genel Toplam & & & & 29.11 & 31.11 \\
\hline
\end{tabular}

olarak bitki örtüsünün toprağı kaplama oranı $\%$ 93.57, ortalama çılak alan oranı ise \% 6.43 olarak hesaplanmıştır. Toprağı kaplama oranı bakımından en yüksek değeri \% 64.46'lık oranla 
istilacı bitkiler göstermiş, istilacı bitkileri \% 14.59 ve $\% 14.52$ 'lik oranlarla çoğalıcı ve azalıcı bitki türleri takip etmiştir (Tablo 2 ve Tablo 3). Ülkemizin değişik yörelerinde yapılan çalışmalarda da istilacı türlerin mera vejetasyonlarının çoğunluğunu oluşturdukları bildirilmiştir (Erden ve ark., 1994; Aydın ve Uzun,
2000; Şahinoğlu, 2010; Uzun ve ark., 2010; Ünal ve ark., 2011; Koç ve Kadıoğlu, 2012; Ünal ve ark., 2012a ve 2012b; Yavuz ve ark., 2012; Ünal ve ark., 2013; Ünal ve ark., 2014; Seydoşoğlu ve ark., 2015; Alay ve ark., 2016; İspirli ve ark., 2016).

Tablo 3. İstilacı türlerin toprağı kaplama (TKO) ve botanik kompozisyondaki oranları (BKO) (\%)

\begin{tabular}{|c|c|c|c|c|c|}
\hline Tür & TKO & $\mathrm{BKO}$ & Tür & TKO & $\mathrm{BKO}$ \\
\hline \multicolumn{6}{|c|}{ İstilacılar } \\
\hline${ }^{1}$ Çal1-ağaç türleri & 38.46 & 41.11 & Carduus nutans & 0.13 & 0.13 \\
\hline Bellis perennis & 2.25 & 2.40 & Eremopoa persica & 0.13 & 0.13 \\
\hline Blysmus compressus & 1.95 & 2.08 & Galium aparine & 0.13 & 0.13 \\
\hline Carex acuta & 1.84 & 1.97 & Helianthemuт nuтmularium & 0.13 & 0.13 \\
\hline Trifolium resupinatum & 1.64 & 1.76 & Trifolium ochroleucum & 0.13 & 0.13 \\
\hline Medicago minima & 1.39 & 1.49 & Myosotis arvensis & 0.11 & 0.11 \\
\hline Trifolium dubium & 0.86 & 0.92 & Sambucus ebulus & 0.11 & 0.11 \\
\hline Galega officinalis & 0.79 & 0.84 & Calamintha grandiflora & 0.09 & 0.10 \\
\hline Ranunculus illyricus & 0.77 & 0.82 & Glaucium corniculatum & 0.09 & 0.10 \\
\hline Astragalus galegiformis & 0.66 & 0.71 & Orchis coriophora & 0.09 & 0.10 \\
\hline Euphorbia helioscopia & 0.66 & 0.71 & Sonchus arvensis & 0.09 & 0.10 \\
\hline Trifolium subterraneum & 0.66 & 0.71 & Centaurium erythraea & 0.07 & 0.08 \\
\hline Carum carvi & 0.55 & 0.59 & Crepis vesicaria & 0.07 & 0.08 \\
\hline Medicago truncatula & 0.54 & 0.57 & Erodium cicutarium & 0.07 & 0.08 \\
\hline Geranium asphodeloides & 0.48 & 0.52 & Medicago polymorpha & 0.07 & 0.08 \\
\hline Ranunculus kotschyi & 0.46 & 0.50 & Orchis palustris & 0.07 & 0.08 \\
\hline Centaurea iberica & 0.45 & 0.48 & Sedum lydium & 0.07 & 0.08 \\
\hline Rumex alpinus & 0.43 & 0.46 & Astragalus angustifolius & 0.05 & 0.06 \\
\hline Taraxacum officinale & 0.41 & 0.44 & Bellardia trixago & 0.05 & 0.06 \\
\hline Crepis armena & 0.38 & 0.40 & Bromus tectorum & 0.05 & 0.06 \\
\hline Trifolium striatum & 0.38 & 0.40 & Cichorium intybus & 0.05 & 0.06 \\
\hline Dryopteris filix-mas & 0.38 & 0.40 & Convolvulus calvertii & 0.05 & 0.06 \\
\hline Eleocharis palustris & 0.36 & 0.38 & Convolvulus elegantissimus & 0.05 & 0.06 \\
\hline Potentilla humifusa & 0.36 & 0.38 & Eryngium billardieri & 0.05 & 0.06 \\
\hline Veratrum album & 0.34 & 0.36 & Euphorbia palustris & 0.05 & 0.06 \\
\hline Lotus angustissimus & 0.34 & 0.36 & Galium album & 0.05 & 0.06 \\
\hline Acinos alpinus & 0.30 & 0.32 & Globularia orientalis & 0.05 & 0.06 \\
\hline Acinos rotundifolius & 0.30 & 0.32 & Helichrysum arenarium & 0.05 & 0.06 \\
\hline Origanum vulgare & 0.29 & 0.31 & Lamium purpureum & 0.05 & 0.06 \\
\hline Sedum album & 0.25 & 0.27 & Lotus ornithopodioides & 0.05 & 0.06 \\
\hline Trifolium hirtum & 0.25 & 0.27 & Salvia forskahlei & 0.05 & 0.06 \\
\hline Bromus arvensis & 0.23 & 0.25 & Tanacetum aucheranum & 0.05 & 0.06 \\
\hline Convolvulus arvensis & 0.21 & 0.23 & Taraxacum farinosum & 0.05 & 0.06 \\
\hline Juncus acutus & 0.21 & 0.23 & Anthoxanthum odaratum & 0.05 & 0.06 \\
\hline Linum flavum & 0.21 & 0.23 & Anagallis arvensis & 0.04 & 0.04 \\
\hline Eryngium campestre & 0.20 & 0.21 & Daphne glomerata & 0.04 & 0.04 \\
\hline Taraxacum scaturiginosum & 0.20 & 0.21 & Wiedemannia orientalis & 0.04 & 0.04 \\
\hline Alchemilla caucasica & 0.18 & 0.19 & Biserulla pelecinus & 0.02 & 0.02 \\
\hline Convolvulus assyricus & 0.18 & 0.19 & Iris galatica & 0.02 & 0.02 \\
\hline Tamarix smyrnensis & 0.18 & 0.19 & Iris pseudacorus & 0.02 & 0.02 \\
\hline Anthemis cotula & 0.16 & 0.17 & Medicago arabica & 0.02 & 0.02 \\
\hline Avena fatua & 0.14 & 0.15 & Satureja spicigera & 0.02 & 0.02 \\
\hline Pilosella hoppeana & 0.14 & 0.15 & Trifolium angustifolium & 0.02 & 0.02 \\
\hline Роа аппиа & 0.14 & 0.15 & Trifolium campestre & 0.02 & 0.02 \\
\hline Bupleurum rotundifolium & 0.13 & 0.13 & Urtica dioica & 0.02 & 0.02 \\
\hline Toplam & & & & 64.46 & 68.89 \\
\hline
\end{tabular}

${ }^{1}$ Fraxinus excelsior, Quercus sp., Acacia sp., Paliurus spina-christi, Eriolobus trilobatus, Prunus spinosa, Smilax excels, Rosa micrantha, Crataegus monogyna, Crataegus orientalis, Rubus discolor 
Botanik kompozisyondaki oranları itibariyle öne çıkan azalıcı türler sırasıyla, Trifolium repens (\% 6.43), Lolium perenne (\% 2.79), Lotus corniculatus (\% 1.56) ve Poa pratensis (\% 1.22) olurken; çoğalıcı türler ise sirasıyla, Cynodon dactylon (\% 7.04), Plantago lanceolata (\% 3.28), Festuca ovina (\% 1.50) ve Dorycnium graecum (\% 0.99) olmuştur. Bellis perennis (\% 2.40), Blysmus compressus (\% 2.08), Carex acuta (\% 1.97), Trifolium resupinatum (\% 1.76$)$ ve Medicago minima $(\% 1.49)$ ise en fazla rastlanılan istilac1 türler olarak kaydedilmiştir (Tablo 2 ve Tablo 3). Bitki türleri bakımından özellikle de otsu istilacı türler, çoğu doğal meralarımız için büyük oranda benzerlik göstermektedir (Ünal ve ark., 2011; Ünal ve ark., 2012a ve 2012b; Yavuz ve ark., 2012; Ünal ve ark., 2013; Ünal ve ark., 2014; Alay ve ark., 2016; İspirli ve ark., 2016).

Vejetasyon etütleri sonrasında yapılan değerlendirme sonucunda 1 mera çok iyi, 1 mera iyi, 6 mera orta ve 7 mera zayif mera durum sınıfında yer almıştır. Çalışmadan elde edilen sonuçlara göre, incelenen meraların 14 adedinin vejetasyonlarının toprağı örtme oranları \% 94 ile 100.00 arasında olup "sağlıklı" meralar sınıfında yer almışlardır. Çaybükü köyünün merası ise \% 47'lik örtü derecesi ile "sorunlu" sinıfta yer almıştır (Tablo 4). Çalışılan meralarda bir BBHB'ne düşen mera alanı 0.03 ile 0.41 hektar arasında değişmektedir. Ancak meraların bulunduğu yağış kuşağı ve mera durum sınıfları dikkate alınarak yapılan hesaplamalara göre (Bakır, 1999; Holechek ve ark., 2010), bir BBHB'ne verilmesi gereken alan 1.9 ile 7.9 ha arasında olması gerekmektedir (Tablo 4). Bu rakamlara göre hayvanların ihtiyacı olan mera alanı ile onlara sunulan mera alanları arasında çok büyük oranda farklılık vardır. Bu nedenle hâlihazırdaki mera alanlarının, mevcut hayvanların ot ihtiyacını karşılamaları hiç mümkün gözükmemektedir.

Meraların bu şekilde yoğun olarak otlatılması, Evans (1998) ve Heathwaite ve ark. (1990)'nın da ifade ettiği gibi meraların bozulmasına yol açmıştır. Nitekim Tablo 4'te görüleceği üzere çalışılan meraların yarısı zayıf mera sınıfında yer almıştır. Diğer yandan Han ve ark. (2008), meralarda otlayan hayvan sayısının olması gerekenden daha fazla olmasının bitki örtüsünün bir bütün olarak toprağı kaplama oranını da azaltarak toprak yüzeyini erozyona karş1 korumasız bıraktığını ifade etmişlerdir. Ancak, çalışılan meraların yer aldığı bölgenin iklim değerlerinin özellikle de yağış değerlerinin yüksek ve yıl içerisindeki dağılımının nispeten uygun olması nedeniyle, vejetasyonda yer alan bazı bitki türleri vejetasyondan çekilse dahi, bunların yerlerini, başta çal1-ağaç türleri olmak üzere diğer bitki türleri hızla doldurmuş dolayısıyla bu alanların bitki örtüsünün toprağı kaplama değerleri daima yüksek kalmıştır.

Diğer yandan meraların çok parçalı yapıları da bu alanların düzenli otlatılması ve 1slah çalışmalarının önündeki en büyük engeldir. Çalışılan meraların parsel sayısı 3 ile 24 arasında değişmektedir (Anonim, 2016b). Yoğun olarak otlatılmaları neticesinde vejetasyonları bozulan meraların; çok parçalı ve alan olarak ta küçük olmaları nedeniyle (Tablo 5) artık otlatma amaciyla kullanılmamaktadır. $\mathrm{Bu}$ durum süksesyonun doğal süreci içerisinde bu alanlarda çalı-ağaç türlerinin varlığını artırmalarına, dolayısıyla mera vasfindan uzaklaşarak ormanlık

Tablo 4. Vejetasyon etüdü yapılan meraların durum ve sağlık sınıfları

\begin{tabular}{|c|c|c|c|c|c|c|c|c|}
\hline Mera adı & ${ }^{1} \mathrm{HKTO}$ & ${ }^{2} \mathrm{TKO}$ & $\begin{array}{c}{ }^{3} \text { Transfer } \\
\text { edilmiş } \\
\text { TKO }\end{array}$ & $\begin{array}{c}\text { Mera } \\
\text { durumu } \\
\text { sinıfi }\end{array}$ & $\begin{array}{c}\text { Mera } \\
\text { sağlığ1 } \\
\text { sınıfı }\end{array}$ & $\begin{array}{l}\text { BBHB'ne } \\
\text { düşen alan } \\
\text { (ha) }\end{array}$ & $\begin{array}{l}\text { BBHB'ne } \\
\text { verilmesi } \\
\text { gereken } \\
\text { alan (ha) }\end{array}$ & $\begin{array}{c}\text { Çalı- } \\
\text { ağaçs1 } \\
\text { türler } \\
(\%)\end{array}$ \\
\hline Çakırkadı & 5.00 & 100 & 73.76 & Zayıf & Sağlıklı & 0.03 & 7.9 & 75 \\
\hline Beşköprü & 26.86 & 94 & 67.89 & Orta & Sağlıklı & 0.41 & 3.9 & 20 \\
\hline Çiftlik & 36.58 & 95 & 68.87 & Orta & Sağlıklı & 0.07 & 3.9 & 28 \\
\hline Akmanlar & 21.65 & 97 & 70.82 & Zayıf & Sağlıklı & 0.04 & 7.9 & 50 \\
\hline Kocareis & 25.52 & 96 & 69.85 & Orta & Sağlıklı & 0.27 & 3.9 & 40 \\
\hline Kabagöz & 40.46 & 97 & 70.82 & Orta & Sağliklı & 0.05 & 3.9 & 45 \\
\hline Tabanözü & 3.16 & 95 & 68.87 & Zayıf & Sağlıklı & 0.08 & 7.9 & 80 \\
\hline Gökçekıran & 26.77 & 99 & 72.78 & Orta & Sağlıklı & 0.03 & 3.9 & 30 \\
\hline Çukurbük & 69.70 & 99 & 72.78 & İyi & Sağlıklı & 0.04 & 2.6 & 0 \\
\hline Çaybükü & 13.30 & 47 & 21.92 & Zayıf & Sorunlu & 0.12 & 7.9 & 12.5 \\
\hline Ahmetler & 18.88 & 98 & 71.80 & Zayıf & Sağlıklı & 0.29 & 7.9 & 64 \\
\hline Dallıca & 35.31 & 97 & 70.82 & Orta & Sağlıklı & 0.04 & 3.9 & 24 \\
\hline Çeştepe & 15.36 & 96 & 69.85 & Zayıf & Sağlıklı & 0.05 & 7.9 & 70 \\
\hline Yeğenli & 85.50 & 100 & 73.76 & Çok iyi & Sağlıklı & 0.15 & 1.9 & 0 \\
\hline Dirazlar & - & 100 & 73.76 & Zayıf & Sağliklı & 0.06 & 7.9 & 100 \\
\hline
\end{tabular}

${ }^{1}$ HKTO: Hesaba katılan (Azalan+çoğalan) bitki türlerinin oranı (\%), ${ }^{2}$ TKO: Toprağı kaplama oranı (\%) 
alana dönüşümüne neden olmaktadır. Nitekim üzerinde hayvan otlatılmayan bu meraların vejetasyonlarındaki ağaç-çalı oranı ortalaması -1slah çalışması yapılıp üzerinde suni mera teşkil edildiği için otlatılmayan Yeğenli merası hariç\% 65.30'dur. Bu değer çalıșılan 15 köyün ortalamasından daha yüksektir (Tablo 3 ve Tablo 4). Çalışma yapılan meraların bazılarında yukarıda ifade edilen sebeple otlatma yapılmaması, buralarda otlayan hayvan türleri içerisindeki keçi oranının azlığı ve diğer ekolojik faktörlerin de etkisiyle çalı ve ağaçsı bitki türlerinin botanik kompozisyonda \% 41.11 gibi yüksek bir oran teşkil etmeleri üzerinde dikkatle durulması ve çözüm üretilmesi gereken bir problem olarak göze çarpmaktadır. Esasen mera durumu sınıflamasında meraların zayıf kategoriye girmesinin en büyük sebebi bu bitki türleridir. Bu noktada, otlamada çalı ve diğer hayvanların otlamaktan kaçındığ birçok yabancı otu tercihen otlayan, bu bakımdan birlikte otladıkları diğer hayvan türleri ile rekabeti minimum olan, hatta onların performansını dahi artırabilen ve mera toprağının sıkışmasında yok denilecek kadar bir etkiye sahip olan keçilerin doğru politikalarla sayılarının artırılması faydalı olabilecektir (Uzun ve ark., 2015). İstatistiklere bakıldığında çalışma yapılan tüm köylerde büyükbaş hayvanlar mevcutken, sadece 5 köyde küçükbaş hayvan vardır ve BBHB değeri üzerinden toplam hayvan varlığının sadece \% 1.16'sını oluşturmaktadır (Anonim, 2016b). Esasen Karadeniz bölgesindeki meraların çalı-ağaç türleri ile istila edilmeleri sürecinin altında yatan en büyük sebep te -diğer ekolojik faktörlere ilave olarak- otlayan hayvan türlerinin bu dağılımıdır. Yani bu istilacı türler, Hickman ve ark. (2004)'nın da ifade ettiği gibi mera vejetasyonuna dâhil olarak merayı bozmaktan daha ziyade, meralar bozulduğu için bu alanları istila etmişlerdir.

Çalışmada yer alan meraların rakım değerleri 8 ile $166 \mathrm{~m}$, yerleşim yerlerine olan uzaklıkları ise 0.2 ile $3 \mathrm{~km}$ arasında değişmiştir. Genel olarak Kuzey bakılara sahip, orta derecede eğimli, orta derinlikte toprak profiline sahip olan meraların 2 tanesinde çok yoğun, 2 tanesinde yoğun, 4 tanesinde orta, 1 tanesinde hafif otlatma yapilırken, 6 tanesinde ise hiç otlatma yapılmamaktadır (Tablo $5)$.

Çakırkadı, Akmanlar, Tabanözü, Ahmetler ve Çeştepe köylerinin meraları sağlık açısından iyi durumda olmalarına rağmen, vejetasyonlarında yer alan kaliteli bitkilerin oranları istenilen durumda değildir ve durum sinıflamasında en alt değer olan “zayıf” sınıfta yer almışlardır. Çaybükü köyünün merası ise gerek toprağı kaplama ve gerekse vejetasyonda yer alan bitkilerin kalitesi açısından en düşük değerlere sahiptir. Dere kenarında olması nedeniyle sik sik sel basmalarına maruz kalan Çaybükü köyünün mera toprağı oldukça taşlık, organik maddesi çok zayıf, sığ ve üzerinde hiç otlatma yapılmamasına rağmen (Tablo 5) bitki örtüsü bakımından oldukça zayıftır (Tablo 4).

En yoğun otlatma yapılan 2 köy merasından birisi olan Kabagöz köyü merasının toprağı 4 puan ile en fazla sıkışma gözlemlenen mera olmuştur (Tablo 5). Kenneth ve ark. (2009)'nın ifade ettiği şekilde, çalışma yapılan meralardaki toprağ kaplama oranı ile toprak derinliği $\left(r=0.553^{*}\right)$ arasında pozitif bir korelasyon tespit edilmiştir. Çalışmada ayrıca, otlatma derecesi ile mera toprağının sıkıșması $\left(r=0.587^{*}\right)$ arasında da pozitif korelasyon bulunmuştur. Korelasyon değerleri

Tablo 5. Vejetasyon etüdü yapılan meraların coğrafi özellikleri ve otlatma dereceleri

\begin{tabular}{|c|c|c|c|c|c|c|c|c|c|}
\hline Mera adı & $\begin{array}{c}\text { Hayvan } \\
\text { sayısı } \\
(\mathrm{BBHB})\end{array}$ & $\begin{array}{c}\text { Mera } \\
\text { alanı/parsel } \\
\text { say1s1 (ha) }\end{array}$ & $\begin{array}{c}\text { Rak1m } \\
\text { (m) }\end{array}$ & $\begin{array}{c}\text { Köye } \\
\text { uzaklık } \\
(\mathrm{km})\end{array}$ & Yöney ${ }^{1}$ & $\begin{array}{c}\text { Eğim } \\
(\%)\end{array}$ & $\begin{array}{c}\text { Toprak } \\
\text { derinliği }\end{array}$ & $\begin{array}{l}\text { Otlatma } \\
\text { derecesi }\end{array}$ & $\begin{array}{c}\text { Toprak } \\
\text { S1kışması }\end{array}$ \\
\hline Çakırkadı & 611 & $19.6 / 7$ & 144 & 3 & $\mathrm{~K}$ & Orta & Orta Derin & Yoğun & 0 \\
\hline Beşköprü & 113 & $46.2 / 11$ & 8 & 1 & GB & Orta & Çok S1 ̆̆ & Orta & 3 \\
\hline Çiftlik & 267 & $17.9 / 10$ & 41 & 1 & $\mathrm{D}$ & Orta & Orta Derin & Orta & 0 \\
\hline Akmanlar & 490 & $16.9 / 24$ & 65 & 0.2 & Düz & Düz & $\mathrm{S} 1 \mathrm{~g}$ & Orta & 1 \\
\hline Kocareis & 155 & $41.1 / 22$ & 22 & 3 & $\mathrm{G}$ & Dik & $\mathrm{S}_{1} \mathrm{~g}$ & Yoğun & 1 \\
\hline Kabagöz & 603 & $30.7 / 3$ & 13 & 1 & Düz & Düz & Orta Derin & Çok yoğun & 4 \\
\hline Tabanözü & 661 & $54.9 / 10$ & 20 & 1 & $\mathrm{~K}$ & Orta & Orta Derin & Yok & 0 \\
\hline Gökçekıran & 410 & $11.4 / 9$ & 138 & 0.5 & $\mathrm{~K}$ & Dik & $\mathrm{S} 1 \breve{\mathrm{g}}$ & Hafif & 1 \\
\hline Çukurbük & 271 & $10.9 / 3$ & 64 & 1.5 & G & Orta & Orta Derin & Orta & 0 \\
\hline Çaybükü & 347 & $42.6 / 7$ & 34 & 1 & Düz & Düz & Çok Sĭg & Yok & 0 \\
\hline Ahmetler & 68 & $19.8 / 9$ & 166 & 3 & $\mathrm{KD}$ & Dik & Orta Derin & Yok & 0 \\
\hline Dallica & 300 & $11.2 / 14$ & 105 & 1 & $\mathrm{G}$ & Orta & $\mathrm{S} 1 \breve{g}$ & Çok yoğun & 1 \\
\hline Çeştepe & 260 & $11.6 / 5$ & 85 & 1 & KB & Orta & Orta Derin & Yok & 0 \\
\hline Yeğenli & 283 & $43.5 / 11$ & 65 & 1 & $\mathrm{D}$ & Hafif & Orta Derin & Yok & 0 \\
\hline Dirazlar & 421 & $27.1 / 9$ & 86 & 1 & $\mathrm{~K}$ & Dik & $\mathrm{S} 1 \breve{\mathrm{g}}$ & Yok & 0 \\
\hline
\end{tabular}


bitki örtüsünün toprak erozyonuna olan direnci artırdığını açık bir şekilde göstermektedir (Bilotta ve ark., 2007). Diğer yandan, Amiri ve ark. (2008), otlatma yoğunluğundaki artışın, toprağın fiziksel özelliklerine olumsuz yönde etkide bulunduğunu ifade etmişlerdir. Faizul ve ark. (1995) da, otlatma derecesinin artışının toprak organik maddesini azalttığını bunun da mera toprağındaki sıkışmayı kolaylaştırıcı etkide bulunduğunu bildirmişlerdir. Hanselka ve ark. (2016) ise, hava ve suyu tutmak için toprak partikülleri arasında yeterli miktarda boşluk bulunmayan sıkışmış topraklarda bitkilerin sağlıklı bir kök gelișiminin olmayacağı, suyun toprak içindeki yatay ve düşey hareketinin kısıtlanacağını, su-toprak erozyonunun artacağını, vejetasyondaki istilacı türlerin oranlarının artacağını ve bunların neticesinde de meraların yem üretiminde \% 80'e varan oranlarda düşüşler görülebileceğini ifade etmişlerdir. $\mathrm{Bu}$ bakımdan Beşköprü ve Kabagöz köyü meralarında sıkışma problemlerini giderici çalışmaların yapılması bu meralar için faydalı sonuçlar verebilecektir.

Meraların bulunduğu yerlerin rakım değerlerinin artışı ile tapulu meraların alanları arasında negatif bir ilişki $\left(r=-0.647^{* *}\right)$ belirlenmiştir. Buna göre, alan olarak azalan meraların gerek toprak yapısı, gerekse bitki örtüsünün doğal olarak daha fazla yıpranması beklenmekle birlikte, buralardaki köylerin son 15-20 yıldır işlemeli tarımı terk ederek bu alanları da hayvan otlatmaya açmaları beklenen bu olumsuz etkilenmenin önüne geçtiğini düşündürmektedir (Usal, 2006).

\section{Sonuçar}

Çalışmadan elde edilen verilere göre Çakırkadı, Tabanözü, Çaybükü, Çeştepe, Ahmetler ve Akmanlar köylerinin meraları öncelikli olarak ıslah çalışmasına ihtiyaç duyulan meralar olarak değerlendirilmiştir. $\mathrm{Bu}$ meraların içerisinde Çaybükü köyü merası hem mera durumu ve hem de mera sağlığı kriterleri bakımından en problemli mera olarak öne çıkmaktadır. Çalışılan diğer meralarda ise gerek mera durumu, gerekse mera sağlığı açısından bir problem görülmemektedir. Ancak bu meralarda sürdürülebilirliğin devam etmesi bakımından, en başta otlatmanın doğru bir şekilde planlaması, sonrasında başta gübreleme ve yabancı ot savaşımı olmak üzere bazı bakım ve 1slah işlemlerinin uygulamaya konulması ve ayrıca uygulamaların da zaman zaman güncellenmeleri gerekliliği göz önünde bulundurulmalıdır.

\section{Teşekkür}

Verilerin elde edilmesindeki destekleri için, Bartın Gıda Tarım ve Hayvancılık İl Müdürü Abdulsetter
BAYRAM'a, Şube Müdürü Teoman TUĞ PEHLIVAN ve Ziraat Mühendisi Hüseyin ÖZTÜRK'e; yazım aşamasındaki destekleri için ise, Ondokuz Mayıs Üniversitesi Ziraat Fakültesi Toprak Bilimi ve Bitki Besleme Bölümü Öğretim Üyesi Sayın Prof. Dr. Orhan DENGIZ'e teşekkür ederiz.

\section{Kaynaklar}

Alay, F., İspirli, K., Uzun, F., Çınar, S., Aydın, İ., Çankaya, N., 2016. Uzun süreli serbest otlatmanın doğal meralar üzerine etkileri. Gaziosmanpaşa Üniversitesi Ziraat Fakültesi Dergisi, 33(1): 116124.

Amiri, F., Ariapour, A., Fadai, S., 2008. Effects of livestock grazing on vegetation composition and soil moisture properties in grazed and non-grazed range site. Journal of Biological Sciences, 8(8): 12891297.

Anonim, 1998. Mera kanunu. http://www.mevzuat. gov.tr/MevzuatMetin/1.5.4342.pdf (Erişim tarihi: 23.08.2016).

Anonim, 2005. Toprak ve arazi siniflaması standartları teknik talimatı. http://www. tarim.gov.tr/Belgeler/ Mevzuat/Talimatlar/Toprak Arazi Siniflamasi Standartlari Teknik Talimati ve IlgiliMevzuat_yeni. pdf (Erişim tarihi: 28.09.2015).

Anonim, 2016a. Meteoroloji Genel Müdürlüğü. http://www.mgm.gov.tr/iklim/iklim-siniflandirmalari .aspx?m=BARTIN (Erişim tarihi: 15.07.2016).

Anonim, 2016b. Bartın İl Gıda Tarım ve Hayvancılık Müdürlüğü Kayıtları.

Aydın, İ., Uzun, F., 2000. Lâdik ilçesi Salur köyü merasında farklı 1slah metotlarının ot verimi ve botanik kompozisyon üzerine etkileri. Turkish Journal of Agricultural and Forestry, 24(2): 301307.

Bakır, Ö., 1999. Otlatma Kapasitesi. (Ed: Anonim) Çayır Mera Amenajmanı ve Islahı (Mera Kanunu Eğitim ve Uygulama El Kitabı-1). Matsa Basımevi, Ankara, s.181-206.

Beskow, W.B., 2001. Integration of goats into sheep and cattle grazing systems as a permanent weed control tool. PhD Thesis, Institute of Natural Resources, Massey University, New Zealand.

Bilotta, G.S, Brazier, R.E., Haygarth, P.M., 2007. The impacts of grazing animals on the quality of soils, vegetation, and surface waters in intensively managed grasslands. Advances in Agronomy, 94(2): 237-280.

Çomaklı, B., Fayetörbay, D., Daşçı, M., 2012. Changing of botanical composition and canopy coverage ratio in rangelands at different altitudes. Atatürk Üniversitesi Ziraat Fakültesi Dergisi, 43(1): 17-21.

David, A.P., Jeffrey, E.H., Patrick, S., Mike, P., 2002. Rangeland health attributes and indicators for qualitative assessment. Journal of Range Management, 55(6): 584-597. 
Davis, P.H., 1970. Flora of Turkey and East Aegean Islands. Vol: 3, 518-531, University Press, UK: Edinburg.

Erden, İ., Acar, Z., Manga, İ., Aydın, İ., Özyazıcı, M.A., Akkaş, N., 1994. Samsun koşullarında gübrelemenin doğal mer'anın ot verimi, kalitesi ve botanik kompozisyonuna etkileri üzerinde bir araştırma. Tarla Bitkileri Kongresi, 25-29 Nisan, Çayır-Mer'a ve Yembitkileri Bildirileri, Cilt III, Bornova-İzmir, s. $83-87$.

Evans, R., 1998. The erosional impacts of grazing animals. Progress in Physical Geography, 22(2): 251-268.

Faizul, B., Karlw, D.M., Murray, L., 1995. Livestock grazing impacts on infiltration rates in a temperate range of Pakistan. Journal of Range Management, 46(4): 367-372.

Gökkuş, A., Koç, A., Çomaklı, B., 2000. Çayır-Mer'a Uygulama Kilavuzu. Atatürk Üniversitesi, Ziraat Fakültesi, Yayın No: 142, Erzurum.

Han, J.G., Zhang, Y.J., Wang, C.J., Bai, W.M., Wang, Y.R., Han, G.D., Li, L.H., 2008. Rangeland degradation and restoration management in China. The Rangeland Journal, 30(2): 233-239.

Hanselka, W.C., Livingston, S.D., Bade, D., 2016. Renovation practices to improve rainfall effectiveness on rangeland and pastures. Texas Agricultural Extension Service. http://publications. tamu.edu/FORAGE/PUB forage Renovation $\% 20 \mathrm{Pr}$ actices $\% 20$ to $\% 20$ Improve $\% 20$ Rainfall\%20Effective ness\%20on\%20Pastures.pdf (Erişim tarihi: 15.07.2016).

Heathwaite, A.L., Burt, T.P., Trudgill, S.T., 1990. Land-use controls on sediment production in a lowland catchment, south-west England. In: J. Boardman, I.D.L. Foster, J.A. Dearing Eds.), Soil Erosion on Agricultural Land. John Wiley and Sons Ltd., pp. 70-86.

Hickman, K.R., Hartnett, D.C., Cochran, R.C., Owensby, C.E., 2004. Grazing management effects on plant species diversity in tall grass prairie. Journal of Range Management, 57(1): 58-65.

Holechek, J.L., Pieper, R.D., Herbel, C.H., 2010. Range Management: Principles and Practices ( $6^{\text {th }}$ Edition). Prentice Hall, one Lake Street, Upper Saddle River, Amsterdam.

İspirli, K., Alay, F., Uzun, F., Çankaya, N., 2016. Doğal meralardaki vejetasyon örtüsü ve yapısı üzerine otlatma ve topoğrafyanın etkisi. Türkiye Tarımsal Araştırmalar Dergisi, 3(1): 14-22.

Kenneth, E.S., Pierson, F.B., Robichaud, P.R., 2009. Effect of plant species composition on rangeland hydrology and erosion. $62^{\text {nd }}$ Society for Range Management Annual Meeting, Paper No. 07-9, Albuquerque.

Koç, A., Gökkuş, A., Altın, M., 2003. Mera durumu tespitinde dünyada yaygın olarak kullanılan yöntemlerin mukayesesi ve Türkiye için bir öneri. Türkiye 5. Tarla Bitkileri Kongresi, 13-17 Ekim, Diyarbakır, s. 36-42.
Koç, A., Çakal, S., 2004. Comparison of some rangeland canopy coverage methods. International Soil Congress Natural Resource Management for Sustainable Development, 7-10 June, Erzurum, p. 41-45.

Koç, A., Kadığlu, S., 2012. Some characteristics of an upland rangeland's vegetation in the Eastern Anatolia. The $9^{\text {th }}$ European Dry Grassland Meeting, 19-23 May, Posters, Session 34 Mon. 21, Greece.

Seydoşoğlu, S., Saruhan, V., Mermer, A., 2015. Diyarbakır ili Silvan ilçesi taban meralarının vejetasyon yapısı üzerinde bir araştırma. Türkiye Tarımsal Araştırmalar Dergisi, 2(1): 1-7.

Şahinoğlu, O., 2010. Bafra ilçesi koşu köyü merasında uygulanan farklı 1slah yöntemlerinin meranın ot verimi, yem kalitesi ve botanik kompozisyonu üzerine etkileri. Doktora tezi, Ondokuz Mayıs Üniversitesi, Fen Bilimleri Enstitüsü (Basılmamış), Samsun.

Thornthwaite, C.W., 1948. An approach toward a rational classification of climate. Geographic Review, 38(1): 55-94.

Usal, G., 2006. Toros dağ köylerinde organik tarım yoluyla üretici gelirlerini arttırma olanakları. Doktora tezi, Çukurova Üniversitesi, Fen Bilimleri Enstitüsü, Adana.

Uzun, F., Garipoğlu, A.V., Algan, D., 2010. Meralarımızda görülen sarı peygamber çiçeği (Centaurea solstitialis L.)'nin bitkisel özellikleri ve kontrolü. Anadolu Tarım Bilimleri Dergisi, 25(3): 213-222.

Uzun, F., Garipoğlu, A.V., Dönmez, H.B., 2015. Mera yabancı otlarının kontrolünde keçilerin kullanımı. Uluslararasi Tartm ve Yaban Hayatı Bilimleri Dergisi, 1(1): 40-50.

Ünal, S., Karabudak, E., Öcal, M.B., Koç, A., 2011. Interpretations of vegetation changes of some villages rangelands in Çankırı province of Turkey. Turkish Journal of Field Crops, 16(1): 39-47.

Ünal, S., Mutlu, Z., Mermer, A., Urla, Ö., Ünal, E., Aydoğdu, M., Dedeoğlu, F., Özaydın, K.A., Avağ, A., Aydoğmuş, O., Şahin, B., Aslan, S., 2012a. Ankara ili meralarının değerlendirilmesi üzerine bir çalışma. Tarla Bitkileri Merkez Araştırma Enstitüsü Dergisi, 21(2): 41-49.

Ünal, S., Mutlu, Z., Mermer, A., Urla, Ö., Ünal, E., Özaydın, K.A., Avağ, A., Yıldız, H., Aydoğmuş, O., Şahin, B., Aslan, S., 2012b. Çankırı ili meralarının mera durumu ve sağlığının belirlenmesi üzerine bir çalıșma. Tarım Bilimleri Araștırma Dergisi, 5(2): 131-135.

Ünal, S., Mutlu, Z., Urla, Ö., Yıldız, H., Şahin, B., 2013. Evaluation and determination of rangeland vegetation in Kayseri province. Tarla Bitkileri Merkez Araştırma Enstitüsü Dergisi, 22(2): 86-95.

Ünal, S., Mutlu, Z., Urla, Ö., Yıldız, H., Aydoğdu, M., Şahin, B., Aslan, S., 2014. Improvement possibilities and effects of vegetation subjected to long-term heavy grazing in the steppe rangelands of Sivas. Tarla Bitkileri Merkez Araştırma Enstitüsü Dergisi, 23(1): 22-30. 
UZUN ve ark.

Yavuz, T., Sürmen, M., Töngel, M.Ö., Avağ, A., Özaydın, K., Yildı, H., 2012. Amasya mera vejetasyonlarının bazı özellikleri. Tarım Bilimleri Araştırma Dergisi, 5(1): 181-185. 